Bartın Üniversitesi

Eğitim Fakültesi Dergisi

Cilt 6, Sayı 3, s.804-816, Ekim 2017

BARTIN - TÜRKIYE

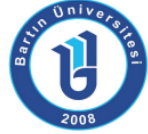

ISSN: 1308-7177

\title{
Yaratıcı Drama ile Üstbilişsel Farkındalığın Geliştirilmesi
}

Seçil HORASAN DOĞAN, Dr. Okt., Gazi Üniversitesi Yabancı Dilller Yüksekokulu, secilhorasan@gmail.com

Pınar ÖZDEMIR ŞIMŞEK, Yrd. Doç. Dr., Hacettepe Üniversitesi, pozdem@hacettepe.edu.tr

Öz: Bu çalışma İngilizce öğretmeni adaylarının üstbilişsel farkındalıklarının yaratıcı drama ile geliştirilmesini amaçlamaktadır. Çalışmaya katılan 10 öğretmen adayı 18 saatlik drama eğitimine katılmıştır. Drama eğitimi öncesi ve sonrasında aynı anket uygulanmış, sonrasında ayrıca görüşme formları doldurulmuş, her atölye bitiminde odak grup tartışmaları yapılmış ve katılımcı ürünleri toplanmıştır. Nicel ve nitel karma analizlerinin sonucunda katılımcıların üstbilişsel farkındalıklarında olumlu yönde bir gelişim olduğu görülmüştür. Ayrıca, katılımcıların sadece akademik ve mesleki farkındalık değil, kişisel gelişim kazandıkları da gözlemlenmiştir.

Anahtar Kelimeler: Yaratıcı drama, üstbilişsel farkındalık, öğretmen eğitimi.

\section{Improving Metacognitive Awareness through Creative Drama}

Abstract: This study aims to improve the metacognitive awareness of English language preservice teachers. 10 pre-service teachers who participated in the study took part in an 18-hour-drama workshop. The same inventory, MAIT, was administered to the participants twice: in the beginning and at the end of the process. Additionally, interview forms were filled in, and focus group discussions were held at the end of each drama session. Finally, drama products were collected. As a result of the mixed method data analysis, it was found that there was a positive improvement in the metacognitive awareness of the participants. In addition, it was were observed that the participants gained not only academic and professional awareness, but also personal development.

Key Words: Creative drama, metacognitive awareness, teacher education. 


\section{GiRiş}

Türkiye'de İngilizce eğitimi ile ilgili yaşanan ciddi sıkıntıların sebeplerinden bazıları uygulama yetersizliği, iletişim ve eleştirel düşünme odaklı olunmaması, öğrencilerin sürece aktif katılamaması ve öğretmen eğitimindeki eksiklerdir (Oktay, 2015; İnceçay, 2012; Demirel, 1983). Yabancı dil eğitiminin öğrenciler için etkili olabilmesi, her şeyden önce bu dersi verecek olan öğretmenlerin en iyi şekilde yetiştirilmesine bağlıdır. Bu bağlamda, öğretmen adaylarının dil öğretme becerilerinin yukarıda belirtilen yönlerde geliştirilmesi gerekmektedir. Eğitimde yaratıcı drama tam da bu eksiklikleri tamamlayabilecek nitelikte güçlü bir araçtır çünkü drama katılımcıyı süreçte aktif kılarak iletişim odaklı, birey merkezli bir eğitim yöntemi sunar (Adıgüzel, 2012). Dramanın bu anlamda İngilizce öğretmeni adaylarına tanıtılması, öğretilmesi ve uygulanması gerekmektedir (Akpınar Dellal ve Kara, 2010; Aşıı̆ı̆lu, 2006). Sadece İngilizce değil, tüm eğitim fakültesi bölümlerinde yaratıcı drama bir disiplin olarak yer almalıdır (Tanrıseven, 2013; Demircioğlu, 2010; Köksal Akyol, 2003).

İngilizce öğretmeni adaylarının yaratıcı dramayı öğrenme ve öğretimlerinde kullanmaları için birçok sebep öne sürülebilir. Bunlardan ilki, yeni bir yaklaşım olarak dramanın öğrenme ve öğretmede kullanılmasının dramanın öğrenci merkezli olması, özgür ve eleştirel düşünmeyi geliştirmesi ve üretken sosyal bireyler yetiştirmesi açısından taşıdığı önemdir (Öztürk, 2001). Ayrıca Yüksek Öğretim Kurumu (YÖK) duygu ve düşüncelerini ifade edebilen, eleştirel düşünen, estetik anlayışa sahip olan, çevresiyle uyum içinde çalışabilen, teoriyi uygulamaya dökebilen öğretmen adayları yetiştirmeyi amaçlamaktadır (Almaz, İşeri ve Ünal, 2014). Bu noktada, çalışmalar İngilizce öğretmeni yetiştiren programların üst düzey düşünme becerileri ile yaratıcı ve eleştirel düşünmeyi desteklemediğini (Hismanoğlu, 2012) ve öğretmenlik becerilerinin kazandırılması için uygulama yapmaya yeterince olanak sağlamadığını (Yavuz ve Zehir Topkaya, 2013; Erozan, 2005) göstermektedir. Bu anlamda yaratıcı drama öğretmen adaylarına uygulama imkanı tanıyan en etkili yöntemdir. Öte yandan, öğretmenlerin "neyi" öğrettikleri kadar "nası"l" öğrettiklerinin de ön planda olması, dramanın öğretmen eğitimindeki önemini artırmaktadır (Özmen, 2010). Bu da öğretmenlik alan bilgisi kadar pedagojik bilginin de gerekliliğini vurgular. Öğretmenlik pedagojik bilgisi, öğretmenin alan bilgisini "nasıl" verdiğini, kullandığı metot ve tekniklerin hedefe uygunluğunu, oluşturduğu öğrenci merkezli işbirlikçi ortamı, verdiği yönergeleri, sesini ve beden dilini, sınıfta oluşturduğu duygusal atmosferi gibi birçok beceriyi içermektedir. Öğretmen adaylarının bu becerileri bilgi düzeyinde edinmeleri yeterli olmayacağı için, uygulamaya dökmeleri anlamında drama eğitimi önemli bir fırsattır.

Bir diğer öğretmenlik bilgisi olan ve üstbilişsel farkındalığın temelini oluşturan öğretmenlik öz bilgisi, her şeyden önce öğretmenin neyi ne kadar bildiğini ve yapabildiğini bilmesi anlamında önem arz etmektedir. İngilizce öğretmenleri ve öğretmen adaylarının drama ile ilgili farkındalıklarını araştıran bir çalışma (Akpınar Dellal ve Kara, 2010) katıımcıların yeterli seviyede farkındalık düzeyinde olduklarını ancak uygulama konusunda kendilerini yeterli görmediklerini göstermektedir. Aşılıoğlu’nun (2006) İngilizce öğretmeni adaylarının öğretim yöntem ve teknikleri konusundaki öz yeterliliklerini araştırdığı çalışma ise katılımcıların kendilerini birçok anlamda yeterli gördüğünü ancak drama kullanımında yeterli görmediklerini ortaya koymaktadır. Araştırmalar gösteriyor ki öğretmen adayları kendi ifadelerinde kendilerini bilgi düzeyinde yeterli görürken uygulamada eksik görmektedir. Yani, sınırlı sayıdaki bu çalışmalar genel olarak İngilizce Öğretmeni adaylarının drama eğitimine daha çok ihtiyacı olduğunu işaret etmektedir.

$\mathrm{Bu}$ noktada öğretmen adaylarının farkındalık düzeyleri, onların öğretmenlik uygulamalarını da olumlu ya da olumsuz yönlerde etkilemektedir. Bu da öğretmen adaylarının farkındalıklarının artırılması gereğini doğurmaktadır. İşte tüm bu gerekçelerde gösterilen 
öğretmenlik becerilerinin sadece bilgi ve teori düzeyinde kalmayıp uygulamaya dökülebilmesi en çok yaratıcı drama ile mümkündür. Uygulamaya dökülen her bir beceri ise onların sadece bilişsel değil, üst bilişsel farkındalıklarını da geliştirecektir.

İngilizce Öğretmenliği programlarında bulunan drama derslerinin eğitsel uygulamalar yerine daha çok edebiyat dersi gibi işlendiği ya da tiyatro metinlerinin incelendiği pasif dersler olarak sürdürüldüğü gözlemlenmektedir. Bu noktada bu çalışma drama derslerini daha eğitsel kılacak uygulamalarıyla ve öğretmen adaylarının mesleki üstbilişsel farkındalıklarına hitap etmesi yönüyle öenm taşımaktadır.

Bu çıkış noktasıyla, çalışmanın amacı İngilizce öğretmeni adaylarının yaratıcı drama ile öğretmenlikte üstbilişsel farkındalıklarının geliştirilmesidir. Diğer bir deyişle, "yaratıcı dramanın öğretmen adaylarının üstbilişsel farkındalıklarına etkisi" araştırma sorusunun temelini oluşturmaktadır. Üstbilişsel farkındalıkları, öğretmenlik mesleğine dair planlama (doğru teknik seçimi), denetleme (anlık karar verme), değerlendirme (gözden geçirme) gibi maddeler açısından incelenmektedir. Araştırmanın varsayımı, planlama, denetleme ve değerlendirme bileşenleri kapsamında üstbilişsel farkındalıklarının yaratıcı drama ile olumlu yönde geliştirilebileceği yönündedir. Araştırmanın sınırlılıkları ise durum çalışması olması yönüyle genelleme yapılamamasıdır.

\section{YARATICI DRAMA VE ÖĞRETMEN EĞiTiMi}

Heathcote'un (1984) çarpıcı bir şekilde dile getirdiği gibi "kitaplarla sınırlı olan ve gerçek hayattan bağımsız olan bilgi ölü bilgidir." Gerçek hayatı öğrenme ortamına taşımak ise, Türkiye gibi geleneksel eğitim anlayışından hala kurtulamamış ülkelerde henüz amaç olma aşamasında kalmıştır. Bu amacın gerçekleştirilebilmesi geleceğin yaratıcı öğretmenlerinin elindedir.

Neden yaratıcı drama? Bu noktada yaratıcı dramanın katkıları tartışılmalıdır.Yaratıcı dramanın öğrencilerin bilişsel, duyuşsal ve psikomotor gelişimlerine katkıları uzun zamandır tartışılmaktadır. Ancak bu etkiler sadece öğrenci üzerinde değil, öğretmen üzerinde de olumlu şekilde yansımaktadır. Yaratıcı dramanın hem öğretmenlik becerilerine, öğretmen öz bilgisine ve üst bilişsel farkındalığına hem de kişisel gelişime katkıları çok sayıdadır. Drama bu anlamda yaratıcılığı, hoşgörülü olmayı, öz yeterliliği, ve özgüveni (Tanrıseven ve Aykaç, 2013), etkileşimi, sosyalleşmeyi, demokrasi fikrini, başkalarına saygıyı (Aykaç ve Çetinkaya, 2013), iletişim becerilerini (Er, 2003), problem çözme becerilerini, kendini gerçekleştirmeyi, öğretmenlerinin kişisel gelişimini (Özdemir ve Çakmak, 2008), sosyal becerileri, öz eleştiriyi, çok boyutlu düşünmeyi (Akpınar Dellal ve Kara, 2010), sorumluluk almayı, kendini anlamayı, öz disiplini (Köksal-Akyol, 2003), risk almayı, beden dili kullanımını (Almaz, İşeri ve Ünal, 2014), yazıı ve sözlü becerileri, sınır tanımamayı, psikolojik rahatlamayı, yaparak-yaşayarak öğrenmeyi (Aytaş, 2013), eleştirel düşünmeyi, estetik anlayışı (Yeğen, 2003), işbirliğini (Abu Rass, 2010), grubun parçası olmayı (Başçı ve Gündoğdu, 2011), empati kurmayı, uzun süreli hafızayı (Demircioğlu, 2010), beş duyuyu, saygıyı, hayal gücünü (Genç, 2003), başkalarını dinlemeyi, göz teması kurmayı (Öztürk, 2001), karar verme mekânizmasını (Tate, 2005) geliştirir.

Yapılan araştırmalara göre genel olarak dramanın etkili kullanımına ilişkin pozitif algılar saptanmaktadır (Almaz, İşeri ve Ünal, 2014; Çetingöz, 2012; Aşıı̆ı̆lu, 2006). Farklı alanlardaki öğretmen adaylarının yaratıcı drama yöntemiyle ilgili öz yeterlik algılarını araştıran Almaz, İşeri ve Ünal (2014) olumlu algılar olduğunu tespit etmiştir. Çetingöz (2012) okul öncesi öğretmen adaylarının eğitimde drama kullanılmasına olumlu bakmalarına rağmen dramayı derslerinde kullanma konusunda düşük öz yeterlik algısına sahip olduklarını bulmuştur. Başçı ve Gündoğdu (2011) farkı bölümlerdeki öğretmen adaylarının drama derslerine dair tutumlarını araştırdığında, özellikle fen bilgisi öğretmenliği bölümünde önemli bir fark olduğu görülmüştür. 
Öğretmen adayları dramanın etkili öğrenme ortamı yaratmak için eğlenceli bir araç olduğunu belirtmişlerdir. Okul öncesi öğretmen adaylarının yaratıcı drama tutumlarını araştıran Ceylan ve Ömeroğlu (2011) ise oldukça olumlu sonuçlar bulmuş ve drama eğitiminin daha uzun süreli verilmesi gerektiğini öne sürmüştür. İngilizce öğretmen adaylarının öğretim teknik ve yöntemlerindeki öz yeterlik algılarıyla ilgili yapılan bir araştırma ise adaylar kendilerini bilgi aşamasında yeterli görmelerine rağmen uygulama aşamasında eksik gördüklerini ortaya koymaktadır (Aşılıoğlu, 2006). Genel olarak ulaşılan sonuç, öğretmen adaylarının drama kullanımıyla ilgili pozitif algılara sahip olmalarına karşın dramayı kendi derslerinde kullanma konusunda öz yeterlik algılarının zaman zaman düşük olduğudur.

\section{3. ÜSTBILIŞSEL FARKINDALIK}

Yukarıda bahsedilen olumlu etkilerinden dolayı yaratıcı dramanın İngilizce öğretmen adaylarının üstbilişsel farkındalıklarında olumlu yönde etkili olacağı düşünülmektedir. Peki, üstbilişsel farkındalık nedir? Üstbilişsel farkındalık, genel farkındalığı artırmayı, öz bilgisini ve düzenleme becerileri geliştirmeyi, buna ortam sağlayan öğrenme çevrelerini ön plana çıkarmayı gerektirir (Schraw ve Moshman, 1995). Hacker, Dunlosky ve Graesser'a (1998: 11) göre "Üstbiliş, hem birinin kendi bilgisini, süreçlerini, bilişsel ve duygusal durumlarıyla ilgili bilgisini hem de kendinin bilgisini, süreçlerini, bilişsel ve duyuşsal durumlarını bilinçli bir şekilde ve kasten denetleme ve düzenleme becerisini içerir." Benzer şekilde, üstbilişsel farkındalık ise "Birinin kendi bilgisi, süreçleri, bilişsel ve duyuşsal durumlarının farkında olması ve bunları düzenleyebilmesidir" (Flavell, 1979).

Üstbilişsel farkındalık üç bileşenden oluşmaktadır: üstbilişsel bilgi, üstbilişsel beceri ve üstbilişsel deneyim (Hacker, Dunlosky, ve Graesser, 1998). İlk olarak üstbilişsel bilgi, "neyi" bildiğimizi ifade eden "içerik bilgisi", "nasıl" bilgisini içeren "yöntemsel bilgi" ve "ne zaman" ve "neden" bilgisini içeren "durumsal bilgi" olarak üç türden oluşmaktadır (Schraw ve Moshman, 1995). Yaratıcı drama ile canlandırılması beklenen kısım üstbilişsel farkındalığın "nasıl" kısmını içeren "yöntemsel bilgi" düzeyinde farkındalıktır. İkinci olarak üstbilişsel beceriler, uygun tekniklerin seçilmesi olan "planlama", kişinin kendi anlamasında ve uygulamasındaki eş zamanlı gözlemi ifade eden "denetleme" ve kişinin kendi öğrenmesini değerlendirmesi kapsamında "değerlendirme" becerileri olarak yine üç grupta incelenebilir (Schraw ve Moshman, 1995). Planlama aşaması hazılık kısmını, denetleme aşaması gözlem kısmını ve değerlendirme aşaması uygulama üzerine yansıtma kısmını ifade etmektedir. Üçüncü olarak üstbilişsel deneyim, entelektüel bir girişime eşlik eden herhangi bir bilinçli, bilişsel ya da duyuşsal deneyimi ifade eder (Flavell, 1979). Bu çalışmada üstbilişsel farkındalığın üç aşaması drama atölyelerine aşağıdaki şekilde uyarlanmıştır:

Planlama: Hedef belirleme, kazanıma uygun aktivite seçme,

Gözlemleme: Ses tonu, beden dili, yönerge, zaman, anlık karar verme,

Değerlendirme: Kendini tanıma, değerlendirme.

Hacker, Dunlosky ve Graesser'in (1998) sınıflandırmasına göre, üstbilişsel farkındalığın üstbilişsel bilgi aşaması doğrudan bu çalışmanın gerekçesini oluşturmaktadır. Diğer bir ifadeyle, öğretim öncesi planlama, öğretim sırasında denetleme ve öğretim sonrası değerlendirme öğretmenlerin öğretmenlik becerilerinin farkındalığıyla ilintili olduğundan bu çalışmada uygulanacak olan atölyelerin amacı kısa vadede üstbilişsel farkındalıklarını, uzun vadede öğretmenlik becerilerini geliştirmektir. 


\section{YÖNTEM}

\subsection{Araştırma Modeli}

Bu araştırma bir durum çalışmasıdır. Dolayısıyla genelleme kaygısı taşımamaktadır. Ayrıca ağırlıklı ölçüde nicel bir çalışma olup nitel desenden de elde edilen verilen nicelleştirilmesine dayanmaktadır. Dörnyei'nin (2007) karışık metot araştırma deseni sınıflandırmasına göre ağılıklı nicel (QUAN) ve paralel tutulan destekleyici nitel (qual) çalışmalar (QUAN+qual) şeklinde gösterilebilir.

\section{2. Çalışma Grubu}

Katılımcılar, bir devlet üniversitesinin İngilizce Öğretmenliği Programı 4. sınıf öğrencilerinden gönüllülük esasıyla katılan 22-23 yaşlarında yaklaşık aynı eğitimsel geçmişlere sahip olan 10 öğretmen adayıdır. Katılımcıların belirlenmesinde Dörnyei'nin (2007) sağlıklı bir yöntem olarak tanımladığı basit rastgele örneklem yöntemi kullanılmıştır.

\subsection{Veri Toplama Araçları}

Bu çalışmada çeşitli araçlarla veri toplanmıştır. En temel araç olan "Öğretmenler için Üstbilişsel Farkındalık Ölçeği", Balçıkanlı (2011) tarafından geliştirilmiş olup güvenirlik geçerlik çalışmasında KMO testine göre 0,794 ve Barlett Tkest'e göre 2513,474 güvenirlik bulunmuştur. Anket beş aralıklı likert ölçeği şeklinde olup (1) Tamamen katılmıyorum, (2) Katılmıyorum, (3) Kararsızım, (4) Katılıyorum, (5) Tamamen Katılıyorum ifadelerine dayanmaktadır. Katılımcılara haftada 2 gün 2 saatlik (toplam 18 saat) ücretsiz ve gönüllü drama çalıştayından önce ve sonra bu ölçek uygulanmıştır.

İkinci olarak çalıştay sonunda yapılan görüşmelerde katılımcılara 7 açık uçlu soru ve irdeleyici sorularla ne tür farkındalıklar yarattığı gibi bilgiler tespit edilmeye çalışılmıştır. Yarıyapılandırılmış görüşme verileri görüşme formuna not edilmiştir. Dörnyei (2007) yarı yapılandırılmış görüşmelerin, açık uçlu soru ile hem doğrudan cevaba ulaşması hem de fazladan bilgi almak gerektiğinde irdeleyici sorularla devamını getirmeye elverişli olması yönünden en çok tercih edilen görüşme türü olduğunu belirtmektedir. Bu form araştırmacı tarafından bu çalışmanın intiyaçlarına uygun olarak geliştirilmiştir. Bu sebeple sorular amaçlara uygun yazılan soruların oluşturduğu bir havuzdan seçilerek derlenip uzman görüşüne başvurulmuştur. Görüşmeler, derinlemesine bilgiye ulaşabilmek için Türkçe yapılmıştır.

Odak grup tartışmaları, her drama oturumunun sonunda grupla toplu değerlendirmeler şeklinde yapılmışır. Karşılıklı yorumlarla ve beyin fırtınası yoluyla daha fazla farkındalık oluşturmak için 5-10 dakika süren tartışmalar aşağıdaki sorular odağında çerçevelendirilmiştir:

- Nasıl hissettiniz? Neler öğrendiniz? Sizlere ne kattı? Bugün cebinize ne koyarak atölyeden ayrılacaksınız?

- Mesleki gelişiminize nasıl etkisi oldu? Öğretmen gözüyle size katkıları neler oldu?

- Bugünkü atölyenin konusu sizce neydi?

Son olarak, atölyelerden çıkan bütün katılımcı ürünleri de veri toplama araçlarına eklenmiştir. Bu ürünler arasında çizilen resimler, yazılan şiirler, yapılan listeler, değerlendirmede söylenen fikirler de eklenmiştir. Bu ürünler, farkındalıklarını tespit etmekte ek kaynak olmaktadır.

\subsection{Verilerin Analizi}

Nicel veriler SPSS programında incelenmiştir. Ön-test ve son-test verileri arasında önemli bir fark olup olmadığına bakmak için t-test analiz aracı kullanılmıştır. Nitel veriler ise içerik analiziyle verilerin kodlanması ve sınıflandırılması şeklinde analiz edilmiştir (Dörnyei, 
2007). Ancak daha sonra yüzdelerle nicelleştirilerek sunulmuş ve nitel verilerden alıntılara yer verilmiştir.

\section{BULGULAR}

Yaratıcı drama ile İngilizce öğretmeni adaylarının üstbilişsel farkındalıklarının ne ölçüde geliştiğinin saptanması için esas olarak kullanılan Öğretmenlik Üstbilişsel Farkındalık Ölçeğinden elde edilen verilerin paired t-test aracı ile analizi sonucunda anlamlı bir fark olduğu ortaya çıkmıştır.

Tablo 1 Ön-test ve Son-test Tanımlayıcı İstatistikler

Paired Samples Statistics

\begin{tabular}{llllll}
\hline & & Mean & $\mathrm{N}$ & Std. Deviation & Std. Error Mean \\
\hline \multirow{2}{*}{ Pair 1 } & Ön-test & 2,9250 & 10 &, 54744 &, 17312 \\
& Son-test & 3,7917 & 10 &, 35246 &, 11146 \\
\hline
\end{tabular}

İstatistiki analiz sonuçları Tablo 1'de görülmektedir. Buna göre ön-test ortalaması 2,9 iken son-testin ortalaması artarak 3,7 olmuştur. Yani yaklaşık $\% 16^{\prime}$ ık bir gelişme görülmektedir.

Tablo 2 Ön-test ve Son-test Bağımlı t-test

Paired Samples Test

\begin{tabular}{|c|c|c|c|c|c|c|c|c|c|}
\hline & \multicolumn{5}{|c|}{ Paired Differences } & \multirow[t]{3}{*}{$\mathrm{t}$} & \multirow[t]{3}{*}{$\mathrm{df}$} & \multirow{3}{*}{$\begin{array}{l}\text { Sig. (2- } \\
\text { tailed) }\end{array}$} \\
\hline & & \multirow[t]{2}{*}{ Mean } & \multirow[t]{2}{*}{$\begin{array}{l}\text { Std. } \\
\text { Deviation }\end{array}$} & \multirow[t]{2}{*}{$\begin{array}{l}\text { Std. } \\
\text { Error } \\
\text { Mean }\end{array}$} & \multicolumn{2}{|c|}{$\begin{array}{l}\text { 95\% Confidence } \\
\text { Interval of the } \\
\text { Difference }\end{array}$} & & & \\
\hline & & & & & Lower & Upper & & & \\
\hline $\begin{array}{l}\text { Pair } \\
1\end{array}$ & $\begin{array}{l}\text { Ön-test } \\
\text { son-test }\end{array}$ &,- 86667 & ,64364 & 20354 & $-1,32710$ &,- 40623 & $-4,258$ & 9 & ,002 \\
\hline
\end{tabular}

p: 0,002 < 0,05 olduğundan Ho hipotezi reddedilir. Ön-test ile son-test ortalamaları arasında $\% 95$ güven düzeyinde fark vardır.

Ön-test ve son-test arasındaki farkı ortaya koyması açısından bu çalışmanın esas sonuçlarını Tablo 2 göstermektedir. Buna göre ilk test ve son test arasında anlamlı bir fark vardır. Yani, İngilizce öğretmen adaylarının üstbilişsel becerilerine olumlu yönde bir etkisi olduğu görülmektedir.

Özetle, nicel sonuçlar göstermektedir ki katılımcıların ilk testten sonra yaratıcı drama atölyelerine katılmaları ile üstbilişsel farkındalıklarında \%95 güven düzeyinde anlamlı bir fark oluşmuştur.

İkinci olarak görüşme soruları incelendiğinde, genel olarak ilk göze çarpan sonuç tüm katılımcıların (\%100) yaratıcı drama sürecinden olumlu etkilerle ayrıldıkları yönündeki algılarıdır. İkinci nokta katılımcıların hiç birinin (\%0) okuldaki drama dersi ve bu çalışmadaki drama eğitimi dışında dramayla ilgili bir deneyimi olmamasıdır. Üçüncü nokta bu proje kapsamında verilen drama eğitiminin katılımcıların tamamının (\%100) beklentilerini fazlasıyla karşıladığı yönündedir. Diğer bir algı da \%100 oranında katılımcıların, İngilizce öğretmeni yetiştirme programlarındaki drama derslerinin içeriğinin bu araştırmadaki gibi daha çok uygulama ağırıklı olması noktasında hemfikir olmalarıdır. Son olarak bütün katılımcılar bu eğitimin onların farkındalıklarını geliştirdiğini ve bu gelişimin bu süreçteki başka bir dış etkenden kaynaklanmadığını belirtmiştir. Bulgular daha detaylı incelendiğinde nitel veri kodlama ve sınıflandırma teknikleriyle dört ana tema ortaya çıkmaktadır: 
1. Aktif katılım: Katılımcı, işbirlikçi, iletişimsel ve öğrenci merkezli eğitim sağlaması (\%90)

2. Yaratıcı ve eğlenceli olması: Hem öğrencilerin yaratıcılıklarını geliştirip dersi daha eğlenceli kılması hem de öğretmenin yaratıcılığını geliştirerek öğretmenin de keyif alması (\%80)

3. Alternatif teknik bulma: Mekanik alıştırmalardan kurtulup alternatif teknikler arama, pratik olma, duruma göre anlık kararlar vererek hazırlıksızken bile anlık aktivite uydurma (\%80)

4. Değerlendirme: Kendini yeniden gözden geçirme, farklı gözle bakma, kendine güvenerek öğrenciler karşısında nasıl davranacağını kestirebilme (\%60)

$\mathrm{Bu}$ ana temalar dışında katılımcılardan biri drama sayesinde daha çok empati kurduklarını, biri daha içten ve samimi, ikisi daha işbirlikçi olduklarını, üçü kendilerine daha çok güvendiklerini ve rahat olduklarını, ikisi de öğrencilerle birlikte öğrenebileceklerini belirtmişlerdir. Birlikte öğrenme konusunda, katılımcılardan biri şu ifadeleri kullanmıştır:

"Drama bilen öğretmen sınıfıyla birlikte öğrenir, bilmeyen öğretmen sınıfına öğretir." (K4)

Ayrıca sonuçlar, öğretmen adaylarının dil öğreniminin sadece kâğıt kitap üzerinde olmayacağı, öğrenciyi daha aktif kılmanın yolunun onları iletişime geçirecek etkinliklerden geçtiğini fark etmeleri de sıklıkla tekrarlanan yorumlar arasındadır:

"Bu aldığımız drama eğitimi bize aktivite üretmemiz konusunda çok fikir verdi." (K8)

Bir katıımııını şu sözleri üstbilişsel farkındalığın geliştiğini destekleyen en anlamlı ifadelerdendir:

"Artık kendimi ders sonrasında değerlendiriyorum." (K7)

Katıımcıların kazandığı değerli farkındalıklardan birisi de neyi bilip neyi bilmedikleri ile ilgili öğretmenlik öz bilgisidir. Bunu en açık şekilde ifade eden katılımcı şöyle söylemiştir:

"Beklentilerimden çok daha fazlasını karşıladı. Ufkumun genişlediğini düşünüyorum. Gerçi hala geliştirmem gereken yönlerim var ama en azından bunların farkına vardım." (K10)

Yaratıcı dramanın öğretmen adaylarının öğretmenlik bilgi ve becerilerine katkılarının ne kadar büyük ölçüde olduğunu ise şu alıntılar özetlemektedir:

"Artık gördüğüm her aktiviteyi 'bunu nasıl farklı aktivitelere adapte edebilirim' diye düşünüyorum." (K6)

"Burada öğrendiklerimi stajda uygulamaya çalışıyorum. Olumlu dönütler aldıkça da yaptığım işten daha çok mutlu oluyorum." (K10)

Üçüncü olarak, her oturum sonunda yapılan odak grup tartışmaları atölye videolarından tekrar izlenip katılımcıların yorumları değerlendirildiğinde, katılımcıların yöneltilen tüm sorulara pozitif yönde cevap verdikleri gözlenmektedir. Bu verilerden elde edilen sonuçlar yaratıcı dramanın katılımcılara iki yönlü katkıda bulunduğu saptanmıştır. Bunlar, hem eğlenerek öğrenmesi, yaratıcılığının gelişmesi ve farkındalığının artması anlamında kişisel gelişimlerine hem de ses kullanımı, benden dili farkındalığı ve öğretim teknikleri açısından profesyonel gelişimlerine katkıda bulunduğu şeklinde değerlendirilmiştir. Bu katkılardan bazıları, örneğin kişisel gelişimi profesyonel gelişime aktarma konusundaki eğilimleri, katılımcıların şu ifadelerinden de ortaya çıkmaktadır:

"Çok eğlendim ve çok güzel aktiviteler öğrendim. Bunları gerçek bir sınıf ortamında kullanmak için sabırsızlanıyorum." (K8, 1. Oturum) 

açıklamıştır:

İkinci oturumda, katılımcılardan bir tanesi o atölyeye dair farkındalığını şöyle

"Bir aktivitede çok bağırmak zorunda kalmıştık sesimizi öğrencilere iletmek için. Bu demek oluyor ki bir sorun var dersimizle ilgili, belki de benle ilgili (öğretmen olarak). Bir şeyleri değiştirmeliyim, mesela sesimi ya da tekniğimi." (K9, 2. Oturum)

Beden diliyle ilgili oturumda tüm katılımcının ortak fikrini, katılımcılardan biri şöyle dile getirmiştir:

"Dil öğretimi demek konuşmak, anlatmak demek değildir illa. Beden dilimizle de çok şeyi ifade edebiliriz konuşmadan." (K4, 3. Oturum)

Kazanıma uygun etkinlik seçimi drama da olduğu kadar öğretmenlikte de önemlidir. Bu konuyla ilgili oturumun sonundaki birbirinden değerli yorumlardan birisi de dil becerilerine dikkat çekmektedir:

"Öğrenciye konuşma aktiviteleri için anlamlı bir sebep/hedef vermeliyiz." (K1, 5. Oturum)

Spontane karar vermeyle ilgili kazanımını bir katılımcı şu şekilde ifade etmektedir:

"Yaratıı olmamız, muhtemel sorunlara hızlı çözümler bulabilmemiz lazım." (K7, 6. Oturum)

Zamanla ilgili etkinliklerde katılımcılara özellikle az zaman verilerek hızlı cevaplar istenmiştir. Bu etkinlikle o oturumun kazanımına ulaşıldığını şu yorum göstermektedir.

"Yeterli zaman verilmediğinde öğrencinin cesaretinin kırıldığını fark ettim." (K2, 7. Oturum)

Kendini tanıma ve değerlendirme oturumlarında bazı katılımcılar kendilerini şöyle değerlendirmiştir:

"Ben ve öğretmen olan ben arasında çok fark yoktu. Mesela ben dokunarak iletişimde olmayı sevdiğim için öğrencilerimle el ele bir resim çizdim. Ayrıca gülen yüz çizdim çünkü ben de neşeli biriyim." (K6, 8. Oturum)

Son olarak katılımcı ürünleri de çalışmanın amacına ulaştığını gösterir niteliktedir. Örneğin, sesini etkili kullanma üzerine yapılan farkındalık çalışmalarının değerlendirme aşamasında katılımcılardan bir slogan söylemeleri istendiğinde seslerini yormadan, ne çok bağırarak ne de aynı tonda konuşarak ders işlememeleri gerektiğine dair sloganlar ortaya çıkmıştır. Başka bir atölyede yönerge vermenin doğruları ve yanlışları listesi oluşturulduğunda, katılımcılar hem bilgi düzeyinde bu beklentiyi karşılamış hem de canlandırmalarda bu bilgiyi uygulama düzeyine taşımışlardır. Doğru tekniklerin seçimi konulu atölye sonunda yapılan posterde ise "amaç=etkinlik seçimi" teması ağırlık kazanmıştır. Bir diğer örnek ise zamanı etkili kullanma atölyesinde kazanımlarını yeni bir atasözü yazarak vermeleri istendiğinde, katılımcılardan bir grubun "Dersini iyi zamanla ki dersini iyi yap" gibi farkındalıklarını ortaya koyan ürünler çıkarmalarıdır.

\section{SONUÇ, TARTIŞMA VE ÖNERILER}

Araştırmanın sonuçlarının da gösterdiği üzere, yaratıcı drama İngilizce öğretmen adaylarının üstbilişsel becerileri üzerinde olumlu bir etki göstermiştir. Öğretmen adaylarının üstbilişsel farkındalıkları, kendilerini tanımaları, yani öğretmenlik öz bilgisine sahip olmaları ve de kendi süreçleriyle ilgili denetleme ve düzenleme yapabilmeleridir. Örneğin dersten önce planlama, ders esnasında denetleme, dersten sonra değerlendirme yapabilme becerisi 
üstbilişsel farkındalığın edinilmiş olduğunun göstergesidir. Ayrıca katılımcılar süreçten pozitif algılarla ayrılmışlardır. Diğer bir deyişle, sonuçlar hipotezde varsayıldığı gibi pozitif çıkmıştır.

Üstbilişsel farkındalıkla ilgili, anket sonuçlarında anlamlı bir fark çıkması, yani yaratıcı dramanın üstbilişsel farkındalıklarını olumlu yönde etkilemiş olması bir kaç şekilde açıklanabilir. ilk olarak dramanın etkileşimi, değerlendirmeyi, eleştirel ve yansıtıcı düşünmeyi geliştiriyor olması, sağlıklı sonuçlar elde edilmesini sağlayan en önemli etken olarak değerlendirilebilir. Hismanoğlu'nun (2012) da savunduğu üzere yaratıcı dramanın İngilizce Öğretmeni adaylarının yaratıcı ve eleştirel düşünme becerilerine etkisi bulunmaktadır. Bir diğer sebebi ise drama atölyelerinin katılımcı ihtiyaçlarına yönelik olarak geliştirilmiş olmasıdır. Böylelikle teoride öğrendiklerini uygulamaya dökme şansı bulmuşlardır. Bu sonuç da Almaz, İşeri ve Ünal'ın (2014) uygulamaya yönelik eğitim önerileriyle paralellik göstermektedir.

Ayrıca, üstbilişsel farkındalıklarındaki ilerlemeyi görüşme sonuçları ve grup tartışmaları da ortaya koymaktadır. Bunlara göre katılımcılar her bir atölyeden sonra birçok noktayı bildiklerini fakat uygulamadıklarını fark ettiklerini belirtmişlerdir. Bu da onların farkındalık düzeylerindeki artışı göstermektedir. Bu anlamda sonuçlar Johnson'ın (2002) bulgularıyla da paralellik göstermektedir. Johnson (2002), dramanın üstbilişi artırma potansiyeli olduğunu ve bireylerin kendi düşünme süreçlerini daha derinden anlayabilmelerine olanak sağladığını ortaya koymuştur.

Dikkat çeken bir diğer nokta ise, katılımcıların öğrenci merkezli yaklaşımı ne kadar çok benimsediklerinin ama uygulamasını ne kadar az gördüklerinin tespit edilmesidir. Katılımcıların çoğu, teori bazında aktif katılım, interaktif öğretim, işbirlikçi ve iletişimsel eğitim gibi kavramlarda üst düzey bilgiye sahip olduklarını yorumlarıyla gösterirken, uygulama bazında seçtikleri etkinliklerin kâğıt kalemlerle yapılan bir takım öğrenme teknikleriyle sınırlı olduğu görülmektedir. Ne var ki bu araştırmanın sonunda katılımcıların neredeyse tamamı nasıl daha öğrenci merkezli bir ders planlayabilecekleri konusunda farkındalık kazanlıklarını belirtmişlerdir. Onların kişisel beyanlarının yanı sıra, atölyelerde de bu yöndeki değişimleri gözlemlenmiştir. Katılımcıların algılarının yenilikçi kuram ve yöntemleri uygulama doğrultusunda olması, dramanın etkileşim ve sosyalleşmeyi (Aykaç ve Çetinkaya, 2013), iletişim becerilerini (Er, 2003), sosyal becerileri (Akpınar Dellal ve Kara, 2010), işbirliğini (Abu Rass, 2010), yaparak-yaşayarak öğrenmeyi (Aytaş, 2013) gibi özellikleri teşvik ettiğini bir kez daha ortaya koymaktadır.

Bunun yanı sıra, katılımcıların drama atölyelerinde beklediklerinden fazlasını bulduklarını ifade etmelerinin arka planında aldıkları tek drama eğitimi olan okuldaki drama derslerinin öngörüldüğü gibi işlenmiyor olması yatmaktadır. Zira çalışmalar bu programlardaki drama derslerinin YÖK (2007) tanımına uygun olmaktan ziyade, edebiyat dersi gibi işlendiğini göstermektedir (Özmen, 2010). Çalışmanın sonuçlarına dayanılarak, İngilizce Öğretmenliği Bölümlerinde drama derslerinin edebiyat bazlı değil, dil öğretimindeki eğitsel uygulamaları çerçevesinde yeniden gözden geçirilmesi gerekliliği ortaya çıkmıştır.

Ayrıca drama atölyelerinde, öğretmen eğitimindeki drama dersinde öğrendiklerine kıyasla çok daha pratik, uygulamalı ve etkili öğretim yöntemlerini keşfetme şansı bulmaları, dramaya olan inançlarını artırarak algılarını da pozitif yönde etkilemiştir. Bu durum, ìngilizce Öğretmenliği progrmalarında drama derslerinin eğitsel anlamda revize edilmesinin sadece öğretmenlik becerileri anlamında değil, aynı zamanda öğretmen inançları, öğretmen bilişi, ve öğretmen algıları anlamında da öğretmen adaylarını geliştirebileceği görülmektedir. Özmen (2010) de aynı şekilde, öğretmen adaylarının performans becerilerinin gelişmesinin onların inanç ve değerlerini de geliştirdiğini göstermektedir. Zira bir öğretmenin öğretmenlik kimliğinin en çok öğretmen eğitiminde şekillendiği çok kez ortaya koyulmuştur. 
$\mathrm{Bu}$ çalışma özetle yaratıcı dramanın öğretmen adaylarının üstbilişsel becerilerinin gelişmesinde katkısı olduğunu göstermektedir. Sınırlılık olarak, bu araştırma tek bir grup üzerinde yapılan bir durum çalışması örneğidir. Ancak aynı çalışma kontrol ve deney grupları üzerinde yürütülecek deneysel bir çalışmaya da çevrilebilir. Bu tarz uzun vadeli çalışmalarda, katılımcıların çalışmadan çıkma/ayrılma sayısının azalması için çalışma öncesi tedbirlerin alınması önem arz etmektedir.

Ayrıca bu çalışma İngilizce öğretmen adaylarıyla yürütülmüştür, ancak öğretmenlik mesleğinin icap ettiği genel öğretmenlik becerileri sebebiyle benzer çalışmalar, farklı öğretmenlik alanlarında da uygulanabilir. Dahası, yaratıcı dramanın öğretmen adaylarının öğretmenlik becerilerine etkilerini, öz yeterliklerine etkilerini, ya da öğretmenlik algılarına etkileri de araştırma konuları olabilir.

\section{KAYNAKÇA}

Abu Rass, R. (2010). Drama in chalk and talk classrooms. Journal of Language Teaching and Research, 1(4), 378-381.

Adıgüzel, Ö. (2012). Eğitimde yaratıcı drama. Natürel Yayıncılık, Ankara.

Akpınar Dellal, N., \& Kara, Z. (2010). Awareness levels of foreign language teacher candidates and teachers about drama techniques. Dil Dergisi, 149, 7-29.

Almaz, G., İşeri, K., \& Ünal, E. (2014). Research of the self-efficacy perceptions of teacher candidates towards the usage of creative drama method. International Journal of Languages' Education and Teaching, December, 48-65.

Aşılıoğlu, B. (2006). The perceptions of student teachers of English regarding their competencies in teaching methods and techniques. Eurasian Journal of Educational Research, 22, 1-11.

Aykaç, M. \& Çetinkaya, G. (2013). The effect of creative drama activities on pre-service Turkish language teachers' speaking skills. Turkish Studies- International Periodical for the Languages, Literature, and History of Turkish or Turkic, 8-9, 671-682.

Aytaş, G. (2013). Eğitim ve öğretimde alternatif bir yöntem: Yaratıcı drama. Adıyaman Üniversitesi Sosyal Bilimler Enstitüsü Dergisi, 6(12), 35-54.

Başçı, Z., \& Gündoğdu, K. (2011). The attitudes and opinions of prospective teachers related to drama courses: The case of Atatürk University. Elementary Education Online, 10(2), 454-467.

Balçıkanlı, C. (2011). Meta-cognitive awareness inventory for teachers (MAIT). Electronic Journal of Research in Educational Psychology, 9(3), 1309-1332.

Ceylan, Ş., \& Ömeroğlu, E. (2011). An examination of the attitudes of students and professors at early childhood education programs regarding drama courses at the preschool level. Ahi Evran Üniversitesi Kırşehir Eğitim Fakültesi Dergisi (KEFAD), 12(4), 225-242.

Çetingöz, D. (2012). Pre-school prospective teachers' self-efficacy levels on using the creative drama method. Hacettepe University Journal of Education, 42, 131-142.

Demircioğlu, Ş. (2010). Teaching English vocabulary to young learners via drama. Procedia Social and Behavioral Sciences, 2, 439-443.

Demirel, Ö. (1983). Orta öğretim kurumlarında yabancı dil öğretim ve sorunları. Türk Eğitim Derneği Bilimsel Toplantısı, Ankara.

Dörnyei, Z. (2007). Research methods in applied linguistics. Oxford: Oxford University Press.

Er, A. (2003). Drama ve dil öğretimi: Dramanın sözlü dil öğretimine etkisi. Kazım Karabekir Eğitim Fakültesi Dergisi, 8, 246-254. 
Erozan, F. (2005). Evaluating the language improvement courses in the undergraduate ELT curriculum at Eastern Mediterranean University: A case study. (Yayınlanmamış Doktora Tezi) Orta Doğu Teknik Üniversitesi, Ankara, Turkey.

Flavell, J. H. (1979). Metacognition and cognitive monitoring: a new area of cognitivedevelopmental inquiry. American Psychologist, 34(10), 906-917.

Genç, N. H. (2003). Yabancı dil öğretiminde öğretim tekniği olarak dramanın kullanımı ve bir örnek. Kazım Karabekir Eğitim Fakültesi Dergisi, 8, 267-276.

Hacker, D. J., Dunlosky, J., \& Graesser, A. C. (Eds.). Metacognition in educational theory and practice. Mahwah, NJ: Lawrence Erlbaum Associates Publishers.

Heathcote, D. (1984). Collected writings. Hutchinson, London.

Hismanoğlu, S. (2012). Prospective EFL teachers' views on English language teacher training program. Journal of Research in Education and Teaching, 1(2), 330-341.

Inceçay, G. (2012). Turkey's foreign language policy at primary level: Challanges in practice. International Association of Research in Foreign Language Education and Applied Linguistics ELT Research Journal, 1(1), 53-62.

Johnson, C. (2002). Drama and metacognition. Early Childhood Development and Care, 172(6), 595602.

Köksal-Akyol, A. (2003). Drama ve dramanın önemi. Türk Eğitim Bilimleri Dergisi, 2(1), 179-190.

Oktay, A. (2015). Foreign language teaching: A problem in Turkish education. Procedia-Social and Behavioral Sciences, 174, 584-593.

Özdemir, S. M., \& Çakmak, A. (2008). The effect of drama education on the prospective teachers' creativity. International Journal of Instruction, 1(1), 13-30.

Özmen, K. S. (2010). Teaching as a performing art: Promoting nonverbal immediacy of English teacher trainees. (Yayınlanmamış Doktora Tezi) Gazi Üniversitesi, Ankara.

Öztürk, A. (2001). Eğitim-öğretimde yeni bir yaklaşım: Yaratıcı drama. Kurgu Dergisi, 18, 251-259.

Schraw, G., \& Moshman, D. (1995). Metacognitive theories. Educational Psychology Review, 7, 351373.

Tanrıseven, I., \& Aykaç, M. (2013). Opinions of the university students related to creative drama's contribution to their personal and professional lives. Adıyaman Üniversitesi Sosyal Bilimler Enstitüsü Dergisi, 6(12), 329-348.

Tate, K. J. (2005). A conceptual lens for observing, analyzing, and interpreting data when exploring preservice creative drama. Youth Theatre Journal, 19(1), 151-170.

Yavuz, A. \& Zehir Topkaya, E. (2013). Teacher educators' evaluation of the English language teaching program: A Turkish case. Novitas-ROYAL (Research on Youth and Language), 7(1), 64-83.

Yeğen, G. (2003). Yaratıcı drama. İlköğretim-Online Öğretim Uygulamaları Serisi, 2(2), 1-4.

YÖK (1998). Eğitim Fakültesi Öğretmen Yetiştirme Lisans Programları Mart 1998.

YÖK (2007). Eğitim Fakültesi Öğretmen Yetiştirme Lisans Programları Haziran 2007. 


\section{SUMMARY}

Some of the main reasons why students cannot learn English in Turkey stem from lack of practice, not being oriented on critical thinking and communication, passive students in teachercentered lessons, and deficiencies in teacher education (Oktay, 2015; İnceçay, 2012; Demirel, 1983). In fact, the success of language learning depends critically on teachers that can provide practice, critical thinking, communication, interaction, active participation, and a learner-centered learning atmosphere. In this sense, drama can be used both in language teaching and in teacher education beacuse of its several merits to provide all of these (Öztürk, 2001). However, it was observed that English Language Teaching (ELT) programs in Turkey are not able to promote critical thinking (Hismanoğlu, 2012) and sufficient amount of practice (Yavuz ve Zehir Topkaya, 2013; Erozan, 2005).

While revising ELT programs, it should always be considered that teacher knowledge does not solely include content knowledge regarding the "what" concepts; it also covers the pedagogical knowledge regarding "how" to teach (Özmen, 2010). Thus, teachers' awareness of their teaching skills gain importance. Accordingly, teachers' "self" knowledge needs to be developed because it is closely aligned with teachers' metacognitive awareness (Balçıkanlı, 2011). To this end, creative drama can be an effective tool to improve self knowledge.

The aim of the study is to investigate the effects of creative drama on ELT student teachers' metacognitive awareness based on its three components: planning, monitoring, and evaluation. It is hypothesized that there will be a positive improvement in metacognitive awareness of student teachers.

Metacognitive awareness is "being aware of one's own knowledge, processes, cognitive and affective states as well as of regulation of those" (Flavell, 1979). Hacker, Dunlosky, and Graesser (1998) define three categories: metacognitive knowledge, skills, and experience. On the other hand, Schraw and Moshman (1995) have two dimensions: metacognitive knowledge and metacognitive regulation. The former includes declarative, procedural, and conditional knowledge whereas the latter involves planning, monitoring and evaluation. In this study, the drama sessions were designed based on planning (setting goals and selecting appropriate techniques), monitoring (voice, body, instruction, time, and decision making), and evaluation (knowing and evaluating the self). Thus, they can be adapted to teaching, and can be improved through drama.

This is a case study focusing on a group of people in a limited time. The research is based on mixed method design based mostly on quantitative means. The participants are 10 ELT senior student teachers at a public university selected through simple random sampling.

Data were collected through Metacognitive Awareness Inventory for Teachers (Balçıkanlı, 2011) before and after the drama workshop. There were also semi-structured interviews forms. During the sessions, there were focus group discussions framed on three questions for collaborative brainstorming. Drama products were also collected as supplementary tools.

Quantitative data were analyzed using paired t-test in SPSS and qualitative data were analyzed through content analysis. Expert opinion was consulted for reliability. The participants were explicitly asked if they had been influenced by any other drama-related variables for internal validity.

The results revealed a positive impact of creative drama on ELT student teachers' metacognitive awareness. The participants confirmed that they had not received any other input than this drama workshop. All participants perceived the process as a useful, practical, and effective one for gaining awareness about teaching. In addition, the data led to form four themes of the benefits of drama: promoting active participation, being creative and enjoyable, finding alternative activities spontaneously, and evaluating themselves. These are highly critical especially in terms of monitoring and evaluation components of metacognition. They revealed less improvement in planning dimension, hich could be because they did many practices of lesson planning in their teacher education. 
Additionally, the interview and focus group discussion results showed many instances of how much they benefitted from the creative drama workshop. Some of them stated that they needed more practice to improve themselves as they wished; however, they were content with the awareness they gained in terms of their strengths and weaknesses because so that they could modify themselves more easily.

As a result, it can be suggested that ELT programs should use creative drama more in teacher education to foster metacognitive awareness of student teachers. Also, all teaching fields at the Faculty of Education should incorporate drama activities more in teacher education for educational and developmental purposes. 